\title{
Review on Holographic Techniques for Photolithography
}

\author{
Prof. Dipannita Mondal \\ Assistant Professor, Artificial Intelligence and Data Science Department, D.Y Patil College of \\ Engineering and Innovation Pune India \\ mondal.dipannita26@gmail.com
}

\begin{tabular}{|c|c|}
\hline Article History & Abstract \\
\hline $\begin{array}{l}\text { Article Submission } \\
02 \text { October } 2021 \\
\text { Revised Submission } \\
11 \text { November } 2021 \\
\text { Article Accepted } \\
10 \text { December } 2021 \\
\text { Article Published } \\
20 \text { January } 2022\end{array}$ & $\begin{array}{l}\text { Holographic methods utilizing spatial modulators to supplant the covers in } \\
\text { photolithographic process. PC produced } 3 D \text { images got from two pictures with } \\
\text { known measurements, reproducing a clear visible field Mask and dark prior mask. } \\
\text { The reason for the proposal is to consider the potential outcomes of picture } \\
\text { decrease, through a holographic based optical segment arrangement, produced by } \\
\text { spatial modulators from a CGH (Computer-created Hologram). Comprehend the } \\
\text { outcomes by decreasing the pictures and look at the outcomes acquired. Boundaries, } \\
\text { for example, complexity, goal and least size of the pictures produced from the spatial } \\
\text { modulators will be broke down so as to decide the conceivable outcomes of progress } \\
\text { and the confinements of the procedure applied to photolithography. It is accepted } \\
\text { that the uniform and dainty oppose film can be effectively kept on the filaments by } \\
\text { utilizing the electro-shower covering innovation. Nonetheless, high electronic } \\
\text { voltage and conductive surface are required with the goal that the current smaller } \\
\text { scale structures are exposed to harm. The immediate splash covering is liberated } \\
\text { from electronic and other harm to substrates yet it is influenced by numerous } \\
\text { boundaries including the arrangement thickness and substrate temperature. } \\
\text { Keywords: Holographic technique, Photolithography, viscosity }\end{array}$ \\
\hline
\end{tabular}

\section{Introduction}

Biosensor advancements have been broadly contemplated. They have been founded on electrochemical optical mass touchy and acoustic wave transducers. As of late, nanogap capacitors for direct electrical DNA identification without marking like fluorescent, electrochemical intercalate attractive, nanoparticles and so on have been created and utilized. The dielectric recognition component (capacitance change) of a nanogap sensor guarantees quick and coordinating situ observing of DNA hybridization without a tedious DNA naming method. The Dielectric properties of particles rely upon electron move, nuclear bonds, and the enormous scope atomic structure. Consequently, a detecting component silicon nanogap exhibits manufactured in this examination. The detecting component polysilicon nanogap coordinated with a reference test cathode (gold).

Figure 1 shows the schematic and photograph of the framework. Unadulterated nitrogen is coursed through the warmer nozzle, warmed up and legitimately showered onto the fiber. Two temperature sensors are set at within and outlet of the warmer spout so as to control the temperature of nitrogen stream. The separation between the splash spout and the fiber, the turn speed of the fiber and the output speed of the shower spout can be freely balanced. The photographs of the recently created introduction arrangement of the ceaseless photolithography process. It comprises of units of UV presentation and fiber-backing and transportation. The readied 3D introduction modules are upheld by two quartz square and encompassed by eight UV LED focal point with the goal that the entire surface of the fiber could be uncovered simultaneously. All units could be modified by PC and physically worked. Every UV LED focal point could be autonomously controlled. The procedure stream is appeared in figure 2 . 


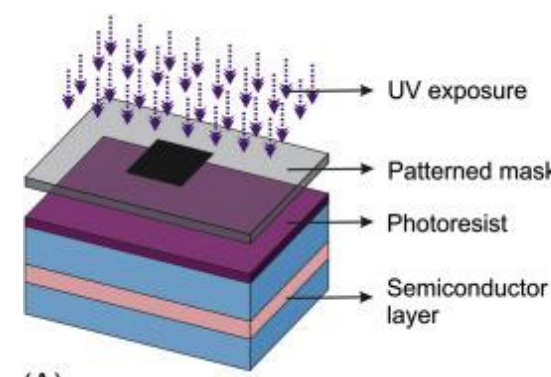

(A)

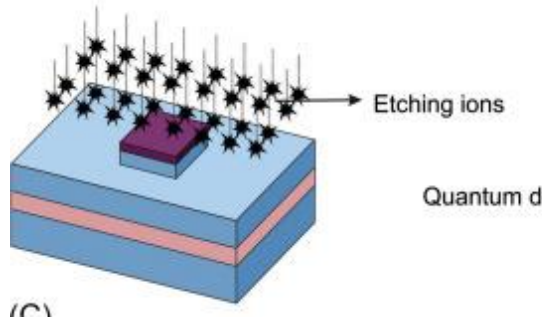

(C)

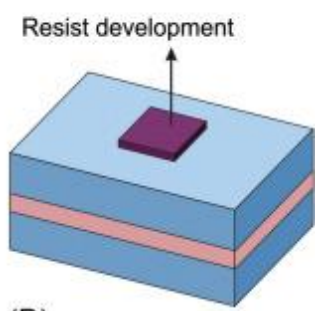

(B)

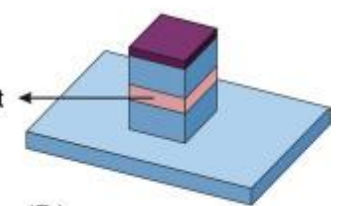

(D)

Figure 1: Holographic photolithography

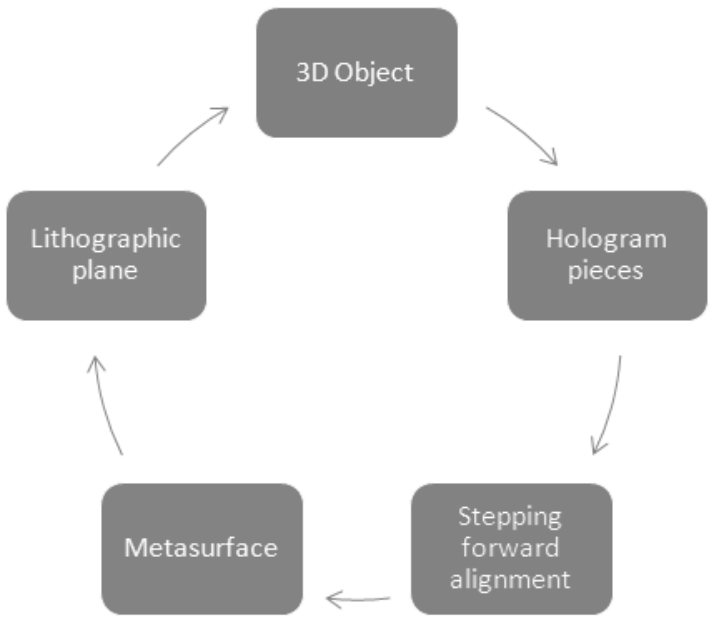

Figure 2: Process involved in Holographic photolithography

The deliberate film thickness with the turn speed of fiber substrates by utilizing the readied oppose arrangements. In spite of the fact that the proportion of slenderer/oppose, the spout/substrate separation and output speed played some impact during the splash statement process, the deliberate film thickness indicated little reliance on the pivot speed when the fiber substrate was $125 \mu \mathrm{m}$ by utilizing AZ5200 slenderer. The deliberate thicknesses of the $\mathrm{CH} 3$ )2CO based arrangement disseminated in a bigger appropriation that those of the AZ5200-based arrangement. The deviation of thickness incompletely came about because of that the little fiber was dependent upon away from the focal situation upon the shower stream.

Decreases of the pictures will be acquired by supplanting the L3 focal point with various central lengths. In the initial step, the central length of focal point L2 and L3 of channel $4 \mathrm{f}$ will be equivalent, $150 \mathrm{~mm}$. Picture decrease will be accomplished by supplanting the L3 focal point with focal points with littler central lengths $(100 \mathrm{~mm}, 50.2 \mathrm{~mm}$ and $25.4 \mathrm{~mm})$. Direct shower covering innovation is alluring for the planning of flimsy oppose movie on the fiber substrate. The tests indicated that slim oppose film could be framed on the $125 \mu \mathrm{m}$ in-distance across fiber without the turn of the substrate. With better covering of the dainty oppose film, the oppose examples of the fiber were improved a lot. This work additionally introduced a recently evolved photolithography arrangement of the fiber substrate. Fine examples of oppose down to $20 \mu \mathrm{m}$ width are effectively framed on the $125 \mu \mathrm{m}$-in-distance across fiber. 


\section{References}

[1] You-Jin Park and Ha-Ran Hwang, "A rule-based simulation approach to scheduling problem in semiconductor photolithography process," 2013 8th International Conference on Intelligent Systems: Theories and Applications (SITA), Rabat, 2013, pp. 1-4, doi: 10.1109/SITA.2013.6560788.

[2] R. F. Marinheiro and M. R. R. Gesualdi, "Holographic techniques using spatial light modulators applied to maskless photolithography," 2017 SBMO/IEEE MTT-S International Microwave and Optoelectronics Conference (IMOC), Aguas de Lindoia, 2017, pp. 1-4, doi: 10.1109/IMOC.2017.8121111.

[3] Y. Zhang, J. Lu, A. Ohtomo, H. Mekaru and T. Itoh, "Continuous photolithography system and technology for fiber substrate," 2011 16th International Solid-State Sensors, Actuators and Microsystems Conference, Beijing, 2011, pp. 370-373, doi: 10.1109/TRANSDUCERS.2011.5969476. 